Weidel, W. \& Primosigh, J. (1958). J. gen. Microbiol. 18, 513-517

\title{
Biochemical Parallels between Lysis by Virulent Phage and Lysis by Penicillin
}

\author{
By W. WEIDEL AND J. PRIMOSIGH \\ Max Planck Institute for Biology, Tübingen
}

In the course of our work on the biochemistry of receptor-active components of the Escherichia coli $\mathbf{B}$ cell wall, bacteriophages quite generally proved to be very useful and sensitive tools for helping to dissect the wall into many different, functionally intact, macro-components. For this discussion the most relevant result of these dissections is the finding that the coli wall is composed of two layers: one is lipoprotein and amounts to about $80 \%$ of the dry weight of the cell wall; the other layer is characterized by a large content of saccharides + lipids + a few typical amino acids which later will be considered more closely. This $20 \%$ layer we have called the lipopolysaccharide layer (Weidel, Koch \& Lohss, 1954).

After removing the lipoprotein layer from isolated cell walls by $90 \%$ phenol, in which it is soluble, the remaining lipopolysaccharide, when viewed under the phase-contrast microscope, appears largely in the form of extremely thinwalled transparent rods. Obviously the lipopolysaccharide layer is rod-shaped as such and forms the supporting framework of the coli wall to which it lends rigidity. The lipoprotein cannot have either of these two properties by itself because of its great plasticity which becomes directly noticeable after removing by dialysis the phenol in which it was dissolved.

The relative positions of these two layers can be ascertained by using phages as indicators. Before phenol treatment the coli wall adsorbs the coliphages T2, T4 and T6. After removing the lipoprotein layer with phenol, T2 and T6 are no more adsorbed by the remainder of the wall, i.e. the lipopolysaccharide, whereas the adsorbability of $\mathbf{T} 4$, as measured by rate of adsorption, is markedly increased. One is led to the conclusion that additional receptor sites for $\mathbf{T} 4$, which all lie in the polysaccharide layer, must have been uncovered and made accessible by removing the lipoprotein. Since the phage particles in these tests can interact with the wall from the outside only, it would follow that the outside is formed largely by the lipoprotein layer which contains the receptor sites for $\mathbf{T} 2$ and $\mathbf{T} 6$ and covers a great deal of the $\mathrm{T} 4$-sites actually present in the lipopolysaccharide layer.

With this picture in mind we now turn to the mechanism of destruction of the double-layered coli wall by certain virulent phages. As early as 1949 we were able to show on electron micrographs that coliphage $\mathrm{T} 2$, after adsorption to coli cell walls, causes structural changes within, and release of material from them (Weidel, 1951). This phenomenon seemed to indicate a specific enzymic activity of the phage particle which might well explain the more general phenomena of virus penetration and lysis 'from within' or 'from without'. 
In order to specify the assumed enzymic activity of T2-particles, the technical problem of labelling coli walls in a really convenient way had first to be solved. The most obvious technique of using isotopes for labelling was employed by Kozloff and co-workers (Barrington \& Kozloff, 1954) who were able to confirm the effect in question and to establish some quantitative relationships between number of phage particles adsorbed/cell wall and amount of wall material released. However, in the course of our investigations on virus receptors, we had come upon a much more tractable method of labelling. Coli cell walls react easily with dinitrofluorobenzene, thus taking on an intense yellow colour, yet without losing their ability specifically to adsorb coliphages T2, T4 and T6, which by the way indicates that for these phages primary amino groups in the wall are not essential to constitute active receptor sites. Upon adsorption, these phage types release soluble yellow material from the yellow di-nitrophenylated DNP walls, and quantitative measurements of enzymic action under different conditions are thus made very easy. All one needs is a photometer. With the help of such dyed-in-thewool coli cell walls we were able to establish three facts, among others, which concern us here (Koch \& Weidel, 1956):

(1) The phage enzyme is not type specific in contrast to the type-specific dependence of phage on their different receptors. Coliphages $\mathrm{T} 2$ and $\mathrm{T} 4$, for instance, attach to chemically very different sites of the coli wall, yet their enzymes remove the same material from the wall.

(2) The receptor sites are therefore obviously not the point of attack of the phage enzyme.

(3) The soluble wall material which appears after phage enzyme action contains three amino acids in comparatively large amounts, namely alanine, glutamic acid and diaminopimelic acid.*

The next step was to find which of the two layers of the coli wall contained especially high amounts of the three amino acids mentioned. No doubt it must be this layer which serves as 'substrate' for the phage enzyme.

Plate 1, fig. 1, shows a two-dimensional paper chromatogram of hydrolysed wall lipoprotein, the phenol-soluble $80 \%$ layer. It offers a complete spectrum of amino acids typical of any average protein and, moreover, diaminopimelic acid is missing. Certainly this cannot be the layer which is attacked by phage enzyme.

Plate 1, fig. 2, shows the chromatogram of hydrolysed lipopolysaccharide, the $20 \%$-layer. Diaminopimelic acid, glutamic acid and alanine form especially large spots. In addition, there is a rather substantial spot of glucosamine, and spots of glycine and lysine are also well marked. Other amino acids are either missing or present in very much smaller amounts. Yet I wish to point out one of the weaker spots, no. 16; this is muramic acid as far as can be said from comparisons with original muramic acid kindly supplied to us by Dr Strange. Its presence will prove to be quite significant.

* The latter compound we thought at first to be cystine, judging merely from the $\boldsymbol{R}_{F^{-}}$ value we found for the DNP-derivative; we are very grateful to Dr Elizabeth Work for drawing our attention to the possibility of a mistake we had made here. 


\section{Biochemical parallels}

Undoubtedly the substrate for the phage enzyme has now been found. But the chromatogram of the lipopolysaccharide presents by itself a rather unexpected discovery. Probably any of the specialists concerned with cell walls would ascribe this chromatogram to a Gram-positive cell wall. Very remarkably, a typically Gram-negative organism like Escherichia coli B hides under a thick cover of lipoprotein a wall which is typically 'Gram-positive' in composition.

It remains to be seen now whether phage enzyme really does act directly upon the 'Gram-positive' lipopolysaccharide layer. Whole phage cannot be used very conveniently for this experiment, since it is impossible to remove the protein coat of the phages from the mixture after their enzyme has acted on the wall layer. Yet the coats have to be removed, or else their amino acids unavoidably obscure the chromatograms later on. A method for obtaining phage-enzyme free from enzymically-inactive phage protein had therefore to be devised. With the help of DNP walls it was found that enzyme is set free from phage particles by freezing and thawing them under certain conditions (Weidel \& Primosigh, 1957). Enzyme solutions prepared by this simple procedure from coliphage T2 contain very little protein but sufficiently high enzymic activity. When mixed with lipopolysaccharide, the enzyme solution dissolves about one-third of the material (dry weight) quite rapidly at $37^{\circ}$, then stops acting further on it. The rest is left in insoluble form and can be removed from the mixture by centrifugation. Both residue and supernatant fluid are then hydrolysed and chromatographed.

Plate 1, fig. 3, shows a chromatogram of the hydrolysed soluble split-product. The complex or complexes cut out from the lipopolysaccharide layer by phage enzyme contain all the amino acids and amino sugars which have been seen to characterize this layer: diaminopimelic acid, glutamic acid, alanine, glucosamine, muramic acid, and small amounts of glycine and lysine. The insoluble residue is almost free from all these components except glucosamine, part of which remains with it. The chromatogram in question, when run at the proper relative concentration, is practically a blank after spraying with ninhydrin. This enzyme-resistant residue is made up mainly from lipid, glucose, L-galaD-mannoheptose and some glucosamine, and it still carries the receptor sites for coliphage $\mathrm{T} 4$ in completely active form. Although the enzyme removes a very substantial amount of material from the lipopolysaccharide layer, it leaves its typical receptor sites untouched. The point of attack of the enzyme appears to be a glycosidic bond, since the soluble split-product has reducing power which is neither found with the insoluble residue nor with the lipopolysaccharide before enzyme treatment.

After having taken apart the coli cell wall in the manner described it may be attempted now to rebuild it from the pieces and to obtain some insight into their structural and functional relationships. As will have been noticed, the qualitative composition of the complex or complexes which phage enzyme cuts out from the coli wall's deeper layer, is most strikingly paralleled by the composition of one of the uridine-5' $\mathbf{5}^{\prime}$-pyrophosphate-linked complexes excreted by Park's penicillin-inhibited Staphylococcus aureus (Park, 1952). In addition, 
one has to take into account that both penicillin and the enzyme of certain virulent phages, under appropriate conditions, cause coli cells to lyse. A closer examination of these conditions is very revealing. Whereas lysis by penicillin requires the cells to be in a state of active metabolism, lysis by phage enzyme on the contrary occurs best when the cells are prevented from metabolic activity. Obviously then, lysis in both cases must be linked to one and the same key component of the cell wall, namely the complex containing the three characteristic amino acids and muramic acid. Under the influence of penicillin, instead of being built into the growing wall, this key component accumulates unused (Park \& Strominger, 1957) and all newly formed pieces of cell wall must thus primarily have abnormal properties. Phage enzyme, on the other hand, removes the key component from normal walls, and if the damage cannot be repaired by replacing the loss, the wall at the point of attack must secondarily acquire the same kind of abnormality which, as can be seen in the phase-contrast microscope, consists in a loss of rigidity. Spherical protrusions appear on the rod-shaped cells which eventually are transformed into large bubbles and may burst in a medium of low osmotic pressure.

Therefore, as the lipopolysaccharide layer of the coli wall was said to be responsible for the rigidity of the whole wall, the often mentioned complexes in turn must be responsible for the rigidity of the lipopolysaccharide layer of which they are an integral part. One may assume that they form bridges between islets of co-polymerized glucose, heptose and lipid, to which they are attached by glycosidic bonds. Schematically, the lipopolysaccharide layer could thus be visualized in the manner shown in Pl. 1, fig. 4. Since phage enzyme not only breaks the bridges but appears to remove them completely, one might expect them to carry the same functional group at both ends. Otherwise one would have to attribute two different specificities to the enzyme, which seems improbable. Sequence analysis of the complexes will clear up this point.

To complete the picture of the coli wall, one only has to smear now a thick layer of plastic lipoprotein over the structure drawn in Pl. 1, fig. 4. It covers many of the islets but not all. Those remaining uncovered expose their receptor sites proper to trap T 4-particles when they come near. T 2- and T6particles are caught by different and probably more numerous sites in the lipoprotein. The enzyme of all three phage types removes the bridges in the near vicinity of the point of attachment of each individual particle (Koch \& Weidel, 1956), thus opening a thoroughfare for the phage particle's DNA to be injected into the cell, which under ordinary conditions rapidly closes the hole again. Only under exceptional conditions when too many bridges are removed by too many adsorbed phage particles and/or when a repair is made impossible, the inside pressure of the cell will rest directly upon the soft lipoprotein, expanding it into the well-known bubbles which eventually burst. This is called lysis 'from without'. On the other hand, lysis 'from within' at the end of the latent period is very probably caused by a massive attack of free phageenzyme which, as shown in our laboratory, is produced in surplus in the infected cell (Koch \& Jordan, 1957). The surplus is not built into completed phage particles. 

Journal of General Microbiology, Vol. 18, No. 2

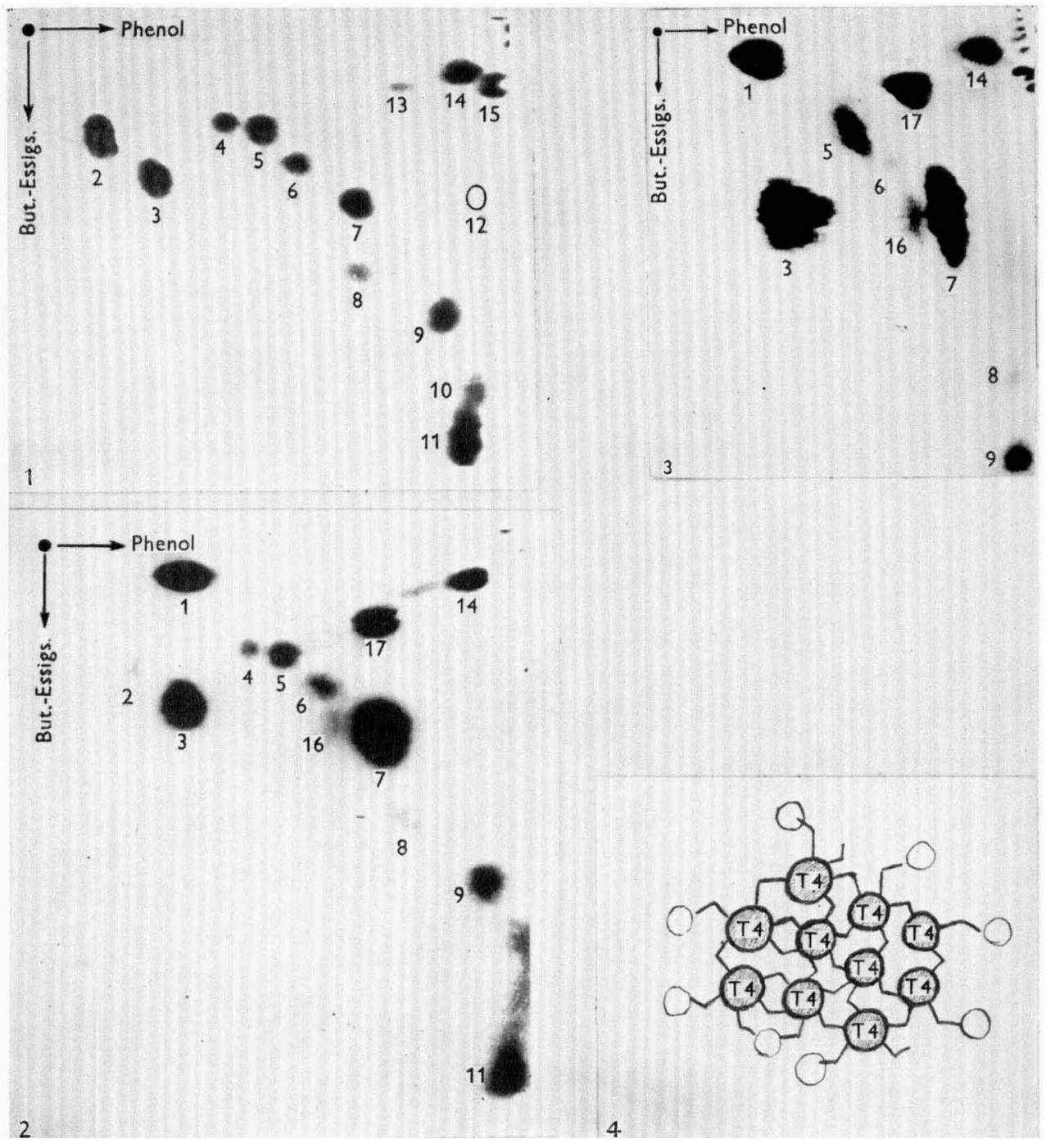

W. Weidel and J, Primosigh-Biochemical parallels. Plate 1 
The same type of lysis is brought about, in our opinion, where penicillin prevents newly synthesized pieces of cell wall from being protected by a rigid inside harness. Again the whole osmotic pressure is exerted upon the yielding lipoprotein, distorting it into so-called protoplasts, or L-forms, which are actually cells still surrounded by a wall, though an incomplete one. Therefore, as long as the lipoprotein can take up and bear the stress without actually bursting, the cell is safe.

The Gram-negative cell, that is Gram-positive cells which lack the additional protection of an expandable outside layer, are doomed once they are forced by active metabolism in the presence of penicillin to extend their habitually naked walls with pieces of new fabric which are easily disruptible. The comparatively high sensitivity to penicillin which is typical of many Gram-positive bacteria, can thus be accounted for.

\section{REFERENCES}

Barrington, L. F. \& Kozloff, L. M. (1954). Action of T2 $\mathbf{r}^{+}$bacteriophage on host-cell membrances. Science, 120, 110.

Koch, G. \& Jordan, E. M. (1957). Killing of $E$. coli B by phage-free T2-lysates. Biochim. biophys. Acta, 25, 437.

Koch, G. \& WeIdel, W. (1956). Abspaltung chemischer Komponenten der Colimembran durch daran adsorbierte Phagen. Z. Naturforsch. 11 b, 345.

PARK, J. T. (1952). Uridine-5'-pyrophosphate derivatives. J. biol. Chem. 194, 877.

PArk, J. T. \& Strominger, J. L. (1957). Mode of action of penicillin. Biochemical basis for the mechanism of action of penicillin and for its selective toxity. Science, 125, 99.

Weidel, W. (1951). Über die Zellmembran von E. coli B. I. Präparierung der Membranen. Analytische Daten. Morphologie. Verhalten der Membranen gegenüber den Bakteriophagen der T-Serie. Z. Naturforsch. 6b, 251.

WeIDEL, W., КосH, G. \& LoHss, F. (1954). Über die Zellmembran von E. coli B. II. Der Rezeptorkomplex für die Bakteriophagen T3, T4 und T\%. Vergleichende chemisch-analytische Untersuchungen. $Z$. Naturforsch. $9 b, 398$.

Weidel, W. \& Primosigh, J. (1957). Die gemeinsame Wurzel der Lyse von E. coli B durch Penicillin oder durch Phagen. Z. Naturforsch. $12 b, 421$.

\section{EXPLANATION OF PLATE}

Fig. 1. Chromatogram of hydrolysate of lipoprotein layer: 2, asp.; 3, glut.; 4, ser.; 5, gly.; 6, threo.; 7, ala.; 8, tyro.; 9, val. + meth.; 10, ph.ala.; 11, leu. +iso-leu.; 12, prol.; 13, hist.; 14, lys.; 15, arg.

Fig. 2. Chromatogram of hydrolysate of lipopolysaccharide layer: 1, diaminopimelic; 16, muramic; 17, glucosamine; others as in Fig. 1.

Fig. 3. Chromatogram of hydrolysate of soluble complexes split from lipopolysaccharide layer by phage enzyme. Numbers as in Figs. 1 and 2.

Fig. 4. Piece of rigid lipopolysaccharide layer of coli B-wall, schematically. Compact particles of co-polymerized glucose, heptose and lipid, carrying receptor sites for phage T 4, are interlaced by bridges made up from components indicated in Fig. 3 . The bridging complexes are removed by phage enzyme. 